ORIGINAL ARTICLE

\title{
A PDGFRA promoter polymorphism, which disrupts the binding of ZNF148, is associated with primitive neuroectodermal tumours and ependymomas
}

\author{
C De Bustos, A Smits, B Strömberg, V P Collins, M Nistér, G Afink
}

J Med Genet 2005;42:31-37. doi: 10.1136/jmg.2004.024034

See end of article for authors' affiliations

\section{Correspondence to:}

Gijs Afink, Department of Oncology-Pathology, Karolinska Institutet, CCK R8:05 KS, 17176 Stockholm, Sweden; gijs.afink@cck.ki.se

Revised version received 22 June 2004

Accepted for publication

6 August 2004
Background: Platelet derived growth factor receptor $\alpha$ (PDGFR $\alpha$ ) expression is typical for a variety of brain tumours, while in normal adult brain PDGFR $\alpha$ expression is limited to a small number of neural progenitor cells. The molecular mechanisms responsible for the PDGFR $\alpha$ expression in tumours are not known, but in the absence of amplification, changes in transcriptional regulation might be an important factor in this process.

Methods and results: We have investigated the link between single nucleotide polymorphisms (SNPs) within the PDGFR $\alpha$ gene promoter and the occurrence of brain tumours (medulloblastomas, supratentorial primitive neuroectodermal tumours (PNETs), ependymal tumours, astrocytomas, oligodendrogliomas, and mixed gliomas). These SNPs give rise to five different promoter haplotypes named $\mathrm{H} 1$ and $\mathrm{H} 2 \alpha-\delta$. It is apparent from the haplotype frequency distribution that both PNET (10-fold) and ependymoma (6.5-fold) patient groups display a significant over-representation of the $\mathrm{H} 2 \delta$ haplotype. The precise functional role in PDGFR $\alpha$ gene transcription for the $\mathrm{H} 2 \delta$ haplotype is not known yet, but we can show that the $\mathrm{H} 2 \delta$ haplotype specifically disrupts binding of the transcription factor ZNF148 as compared to the other promoter haplotypes.

Conclusions: The specific over-representation of the $\mathrm{H} 2 \delta$ haplotype in both patients with PNETs and ependymomas suggests a functional role for the ZNF148/PDGFR $\alpha$ pathway in the pathogenesis of these tumours.
A berrant growth factor signalling is a key event in the development and maintenance of tumours. It can be due to abnormal expression or mutation of the growth factor or its receptor, or activation of downstream signalling pathways.

The platelet derived growth factor (PDGF) family consists of five members, PDGF-AA, - AB, -BB, -CC, and -DD, which bind to two different tyrosine kinase receptors, PDGF receptor $\alpha$ (PDGFR $\alpha)$ and PDGF receptor $\beta$ (PDGFR $\beta)$. In cultured cells, expression of PDGFR $\alpha$ renders a cell responsive to most ( $\mathrm{AA}, \mathrm{AB}, \mathrm{BB}$, and $\mathrm{CC}$ ) PDGF ligands. However, during normal embryonic development it appears that only PDGF-AA and -CC elicit PDGFR $\alpha$ mediated signalling, due to the spatio-temporal distribution of ligands and receptors. Receptor and ligand are typically expressed in separate but adjacent cell layers of the embryo, thus generating paracrine PDGF signalling. ${ }^{1}$ Previous studies have shown that during embryonic development PDGFR $\alpha$ is expressed in oligodendrocyte progenitors, early neuroepithelial cells, and neuronal progenitors, for example, in the cerebellum, while the adult brain shows very low levels of this receptor. ${ }^{23}$

Autocrine PDGF signalling occurs in a wide variety of tumours. ${ }^{4}$ In particular, brain tumours have been well documented to express the components necessary for PDGF signalling. Both low and high grade astrocytomas, ${ }^{5-7}$ oligodendrogliomas, ${ }^{89}$ and ependymal tumours $^{10}$ have been shown to express both PDGF receptors and ligands. Whether there is co-expression of ligands and receptors by the same cell has not been established as yet. In high grade astrocytomas PDGFR $\beta$ is expressed in the hyperplastic capillaries, while PDGFR $\alpha$ and PDGF-A and -B were found to be expressed in most tumour cells. ${ }^{5}$ Cell lines derived from high grade astrocytomas also express at least one of the two PDGF receptors together with one or more of the ligands. ${ }^{71}$
The levels of PDGFR $\alpha$ expression in astrocytic tumours are elevated compared to normal brain; this is due to amplification of the gene in only a small fraction of the tumours. ${ }^{5} 12$ Simultaneous expression of PDGF ligands and receptors also occurs in medulloblastomas and supratentorial primitive neuroectodermal tumours (PNETs). ${ }^{10} 1314$

Mouse models further support a role for abnormal PDGF signalling in brain tumour development. Forced expression of PDGF-B in newborn mouse brains, either by cell type specific or non-specific gene transfer, using retroviral vectors, induces the formation of PDGFR $\alpha$ positive tumours with morphologies similar to many human brain tumours. ${ }^{15}{ }^{16}$ In addition, recently it has been shown that PDGFR $\alpha$ and members of its downstream signalling pathway are involved in the establishment of medulloblastoma metastases. ${ }^{17}$ Together, these studies indicate that PDGFR $\alpha$ may be a key component in the pathogenesis of a variety of brain tumours.

Consequently, we hypothesised that anomalous control of PDGFR $\alpha$ expression might increase the susceptibility of individuals to develop PDGFR $\alpha$ positive brain tumours.

Transcriptional regulation is an important mechanism in regulating protein levels. It contributes to the correct spatiotemporal expression of the PDGFR $\alpha$ gene (PDGFRA) during embryonic development. ${ }^{18} 19$ A number of transcription factors (GATA4, C/EBP, PBX) have been identified which regulate PDGFRA promoter activity in cultured cells in response to extracellular signals. ${ }^{20-23} \mathrm{~A}$ similar role in vivo for these transcription factors remains to be established.

Recently, it has become evident that polymorphisms within the PDGFRA promoter may also affect the transcriptional

Abbreviations: EMSA, electrophoretic mobility shift assay; PDGFR, platelet derived growth factor receptor; PNET, primitive neuroectodermal tumour; SNP, single nucleotide polymorphism 
regulation of this gene. Joosten et $a^{24}$ have characterised a number of polymorphic sites within the PDGFRA promoter, which can be grouped into five haplotypes ( $\mathrm{Hl}, \mathrm{H} 2 \alpha, \mathrm{H} 2 \beta$,

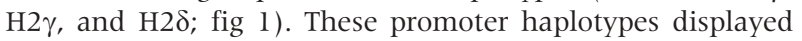
large differences in their ability to drive reporter gene expression when tested in human U2-OS osteosarcoma cells. In addition, the promoter haplotypes with low transcriptional activity were under-represented, whereas those with high transcriptional activity were over-represented in patients with neural tube defects compared to a normal population. The transcription factors involved in this haplotype specific PDGFRA promoter regulation remain unknown.

In our current study we have investigated the link between PDGFRA promoter polymorphisms and brain tumour development. For this purpose we have analysed a panel of low grade astrocytomas, ependymal tumours, medulloblastomas, PNETs, mixed gliomas, and oligodendrogliomas. Our results demonstrate a characteristic over-representation of the $\mathrm{H} 2 \delta$ promoter haplotype in both PNETs and ependymomas. In addition, analysis of haplotype specific binding of transcription factors to the PDGFRA promoter demonstrated that in comparison with the other promoter haplotypes, the $\mathrm{H} 2 \delta$ haplotype promoter specifically fails to bind the transcription factor ZNF148.

\section{METHODS}

\section{Tumour and control DNA}

The tumour (and paired blood when available) samples originate from the Karolinska Hospital in Stockholm, the Uppsala University Hospital in Uppsala, and the Sahlgrenska University Hospital in Gothenburg. Classification of the tumours was performed according to the most recent WHO classification. ${ }^{25}$ We used the following tumour samples (mean age, range low-high): 40 medulloblastomas (10.0, $0.6-38), 12$ PNETs $(8.4,0.2-23), 14$ astrocytomas grade II $(33.9,9-53), 14$ ependymomas $(40.8,14-72)$, eight myxopapillary ependymomas $(39.4,22-66)$, seven subependymomas (52.4, 39-69), one anaplastic ependymoma (7), 20 oligodendrogliomas $(44.6,24-73)$, eight anaplastic oligodendrogliomas (50.3, 7-73), 10 oligoastrocytomas (35.6, 11-70), and four anaplastic oligoastrocytomas $(43.3,25-64)$. The control group blood samples originated from 91 anonymous healthy blood donors at the Uppsala University Hospital.

The control sample blood DNA was extracted according to the protocol described by Miller et al, ${ }^{27}$ while tumour and paired blood DNA samples were prepared as described previously. ${ }^{28}$

Ethical permission was obtained from the ethical boards of Uppsala University Hospital, Karolinska Hospital, and
Sahlgrenska Hospital, as well as from the local research ethical committee at Addenbrooke's Hospital.

PCR amplification and nucleotide sequence analysis Samples (20-100 ng) of genomic DNA were amplified in a $30 \mu \mathrm{l}$ volume containing a primer pair $(4 \mathrm{pmol}$ of each primer), $100 \mathrm{mM}$ deoxyribonucleoside triphosphates, $1 \mathrm{U}$ AmpliTaq Gold (PE Biosystems, Foster City, CA, USA), and $1 \times \mathrm{PCR}$ buffer with $3 \mathrm{mM} \mathrm{MgCl}_{2}$ (PE Biosystems). The PDGFRA promoter single nucleotide polymorphisms (SNPs) were amplified in two separate reactions with the following primer pairs (nucleotide (nt) numbering according to GenBank accession X80389): PDGFRAp-1562F: 5'-TTT GTT CCC GCT CAT TTT CT-3' and PDGFRAp-1340R: 5'-ATG TCA GCC TCG AAA ACA GG-3' (nt 566-790); PDGFRAp-1110F: 5'-TCA GAG AGC GAT GAA GGT GA-3' and PDGFRAp-759R: 5'-TTG TTT TCG GGG TTA TCT GG-3' (nt 1021-1371).

Aliquots $(10 \mu \mathrm{l})$ of the PCR product were checked for size by agarose gel electrophoresis and the remaining product was treated $\left(45 \mathrm{~min}, 37^{\circ} \mathrm{C}\right.$ ) with $1 \mathrm{U}$ exonuclease I (New England Biolabs, Beverly, MA, USA) and 2 U shrimp alkaline phosphatase (Roche, Penzberg, Germany). After an enzyme inactivation step $\left(15 \mathrm{~min}, 80^{\circ} \mathrm{C}\right), 4 \mu \mathrm{l}$ of the PCR product was directly sequenced using BigDye terminator chemistry (PE Biosystems) and one of the PCR primers. The sequencing reactions were run on an $\mathrm{ABI} 377$ automated sequencer (PE Biosystems) and subsequently analysed using Sequence Navigator Version 1.01 (PE Biosystems).

\section{Cell culture and transfections}

The PDGFRA promoter-luciferase plasmids have been described elsewhere, ${ }^{24}$ and the $\beta$-actin promoter-LacZ plasmid was a gift from Dr R de Groot, University of Utrecht. The cell lines D324 Med and NIH3T3 were grown in Dulbecco's modified Eagle medium and the cell line PFSK-1 was grown in RPMI with in both cases the addition of $10 \%$ fetal calf serum. The day before transfection, cells were plated in a six well dish at a cell density of $175 \times 10^{3} /$ well (D324 Med), $275 \times 10^{3} /$ well (PFSK-1), and $300 \times 10^{3} /$ well (NIH3T3). PDGFRA promoter-luciferase plasmid DNA was isolated using the Qiagen High Speed midi-prep kit (Qiagen, Hilden, Germany). DNA from two independent isolations was used in the transfection assays. Transfections were performed using Fugene6 (Roche), following the manufacturer's instructions. Luciferase and $\beta$-galactosidase levels were determined as described..$^{29}$

\section{Electrophoretic mobility shift assay (EMSA)}

Nuclear extracts from PFSK-1 cells were prepared as described. ${ }^{29}$ Oligonucleotides for EMSA were synthesised

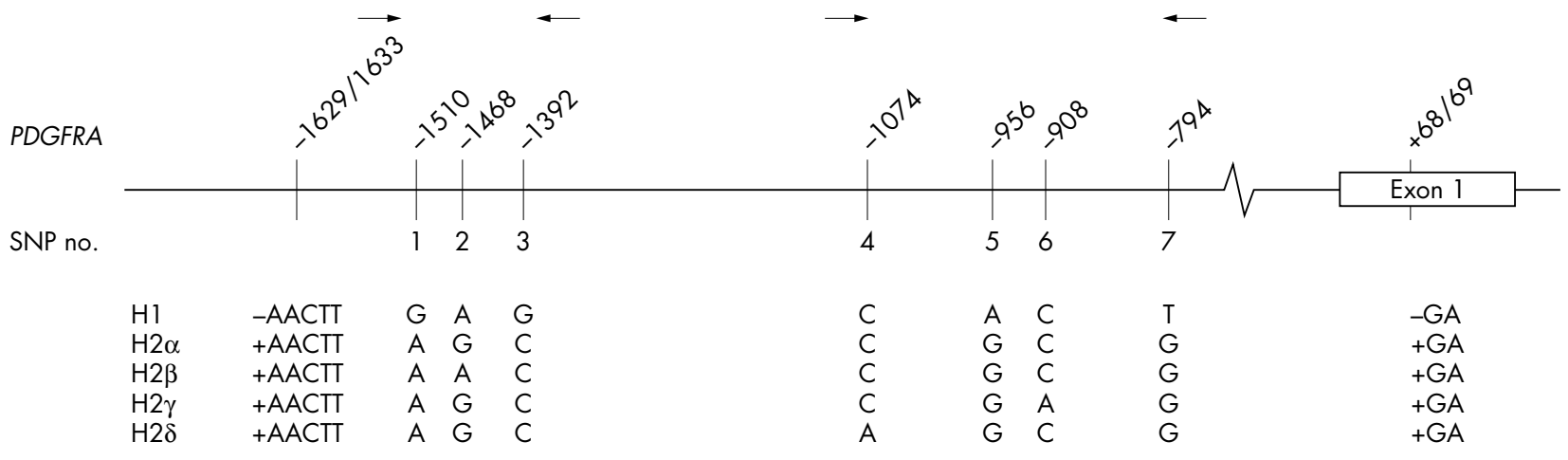

Figure 1 Schematic drawing of the PDGFRA promoter polymorphisms. Nine different polymorphic sites (vertical bars, numbers above refer to the position relative to the transcriptional initiation site; GenBank accession number is X80389) can be identified within the PDGFRA promoter region, of which seven are SNPs (numbered below). These polymorphisms can be grouped into five haplotypes, as indicated by the sequence. The arrows represent the location of the PCR primers used in the present analysis. Adapted from Joosten et al. ${ }^{24}$ 
A

\begin{tabular}{|c|c|c|c|c|c|c|c|c|c|c|c|c|}
\hline & \multicolumn{2}{|c|}{ Control } & \multicolumn{2}{|c|}{ Medulloblastoma } & \multicolumn{2}{|c|}{$\mathrm{PNET}^{1}$} & \multicolumn{2}{|c|}{ Ependymal tumour } & \multicolumn{2}{|c|}{$\begin{array}{l}\text { Diffuse } \\
\text { astrocytoma }\end{array}$} & \multicolumn{2}{|c|}{$\begin{array}{l}\text { Mixed glioma/ } \\
\text { oligodendroglioma }\end{array}$} \\
\hline HI & 36 & 0.1978 & 18 & 0.2250 & 6 & 0.2500 & 10 & 0.1667 & 3 & 0.1071 & 18 & 0.2143 \\
\hline$H 2 \alpha$ & 123 & 0.6758 & 44 & 0.5500 & 14 & 0.5833 & 41 & 0.6833 & 19 & 0.6786 & 55 & 0.6548 \\
\hline H2 $\beta$ & 13 & 0.0714 & 12 & 0.1500 & 0 & 0.0000 & 4 & 0.0667 & 4 & 0.1429 & 9 & 0.1071 \\
\hline $\mathrm{H} 2 \gamma$ & 7 & 0.0385 & 2 & 0.0250 & 0 & 0.0000 & 2 & 0.0333 & 2 & 0.0714 & 2 & 0.0238 \\
\hline$H 2 \delta$ & 3 & 0.0165 & 4 & 0.0500 & 4 & $0.1667^{2}$ & 3 & 0.0500 & 0 & 0.0000 & 0 & 0.0000 \\
\hline Total & 182 & 1.0000 & 80 & 1.0000 & 24 & 1.0000 & 60 & 1.0000 & 28 & 1.0000 & 84 & 1.0000 \\
\hline
\end{tabular}

1) Fisher $5 \times 2, p=0.014$

2) Fisher $2 \times 2, p=0.004$

3) Fisher $2 \times 2, p=0.032$

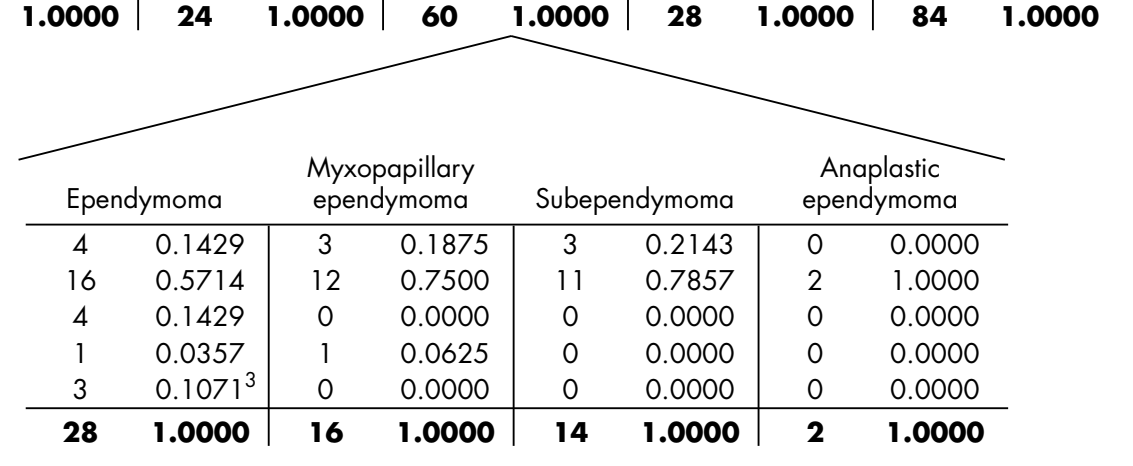

B

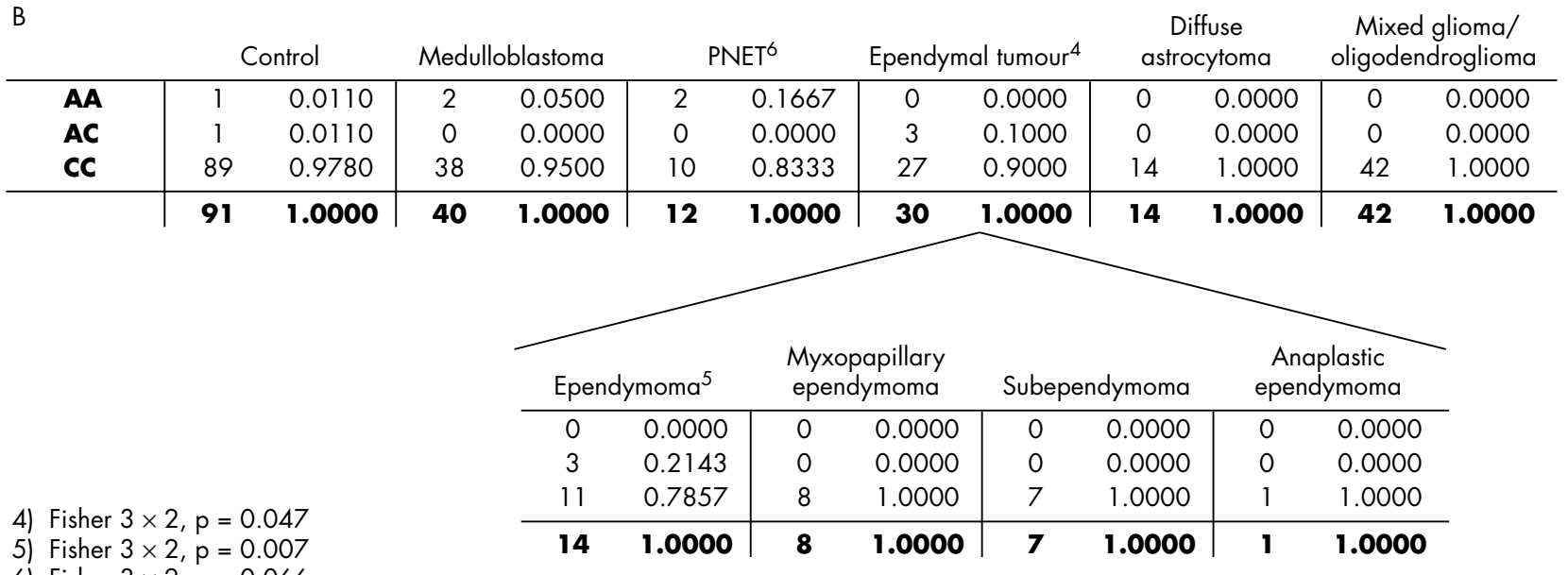

6) Fisher $3 \times 2, p=0.066$

Figure 2 PDGFRA promoter haplotype/genotype frequencies for the control and tumour groups. (A) Distribution of PDGFRA promoter haplotype frequencies. The haplotype frequency distribution of the PNET group differs significantly from the control group (' $p=0.014)$. Within this PNET group, the $\mathrm{H} 2 \delta$ haplotype is 10 -fold over-represented compared to the controls $\left({ }^{2} p=0.004\right)$. The $\mathrm{H} 2 \delta$ haplotype is also over-represented in the grade II ependymomas ( ${ }^{3} p=0.032$ ). (B) Distribution of the SNP4 genotype frequencies. The SNP4 genotype frequency for the ependymal tumours is significantly different from the control group, with an over-representation of the $A C\left(\mathrm{H} 2 \delta\right.$ heterozygotes) genotype $\left({ }^{4} \mathrm{p}=0.047\right)$. This overrepresentation is even more apparent in the ependymoma group $\left({ }^{5} \mathrm{p}=0.007\right)$. The $\mathrm{H} 2 \delta$ homozygous genotype $(\mathrm{AA})$ shows a tendency to be overrepresented in PNETs $\left({ }^{6} p=0.066\right)$.

as single oligonucleotides (DNA Technology, Aarhus, Denmark). They were pairwise mixed at equimolar amounts, incubated for $5 \mathrm{~min}$ at $100^{\circ} \mathrm{C}$, and annealed using a decreasing temperature gradient. The following sequences represent only one strand of the complementary oligonucleotides (nt 1046-1065 of GenBank accession X80389): SNP4C: 5'-CTC CCC TCC CCC GCT GTC GC-3'; SNP4A: 5'-CTC CCC TCC CAC GCT GTC GC-3'; SNP4MI: 5'-CTC CCC TCA CCC GCT GTC GC-3'; SNP4M2: 5'-CTC CCC TCC CCC ACT GTC GC-3'.

A double stranded consensus SPl oligonucleotide $\left(5^{\prime}\right.$-ATT CGA TCG GGG CGG GGC GAG C-3') was purchased from Promega (Madison, WI, USA).

Double stranded oligonucleotides were labelled using polynucleotide kinase (New England Biolabs, Beverly, MA,
USA) and $\gamma^{32}$ P-ATP (Amersham, Uppsala, Sweden). A 1-2 $\mu \mathrm{l}$ sample of nuclear extract was used in a $20 \mu \mathrm{l}$ EMSA reaction containing $20 \mathrm{mM}$ Hepes pH 7.9, $100 \mathrm{mM} \mathrm{NaCl}, 35 \mathrm{mM} \mathrm{KCl}$, $5 \mathrm{mM} \mathrm{MgCl}_{2}, 1 \mathrm{mM}$ DTT, $10 \%$ glycerol, $1 \mu \mathrm{g}$ poly(dI$\mathrm{dC}$ ).poly(dI-dC) (Amersham Biosciences, Uppsala, Sweden), and $0.01 \mathrm{pmol}$ labelled oligonucleotide. The reactions were incubated for $20 \mathrm{~min}$ at room temperature and subsequently analysed on a $4 \%$ native polyacrylamide gel.

\section{Matlnspector analysis}

Analysis of the SNP4 containing sequence (nt 1046-1065 of GenBank accession X80389) for putative transcription factor binding sites was performed using Genomatix Matinspector professional release 6.2.1. ${ }^{30}$ We used a threshold of 0.75 for core similarity and the optimised setting for matrix similarity. 


\section{RESULTS \\ PDGFRA promoter haplotypes and genotypes in human brain tumours}

The PDGFRA promoter region contains a number of polymorphisms, which can be organised into two subfamilies, $\mathrm{Hl}$ and $\mathrm{H} 2$, as shown in fig 1 . The H2-subfamily can be further divided into four variants, thus creating a total of five different haplotypes. Since previous studies ${ }^{24}{ }^{31}$ have indicated that the PDGFRA promoter haplotype distribution may be geographically specific, we first analysed the PDGFRA promoter haplotype distribution in a Swedish population. For this purpose we amplified the PDGFRA promoter region containing SNP1 through SNP6 (which enables us to distinguish all five haplotypes) from 91 control samples and determined the haplotypes by nucleotide sequence analysis. As shown in fig $2 \mathrm{~A}$, more than $87 \%$ of the haplotypes are either $\mathrm{Hl}$ or $\mathrm{H} 2 \alpha$, while the $\mathrm{H} 2 \beta, \mathrm{H} 2 \gamma$, and $\mathrm{H} 2 \delta$ haplotypes account for small fractions of the total. The nucleotide sequence analysis of the control samples did not give any indications of the existence of additional polymorphisms in the promoter region or of additional haplotypes.

Subsequent analysis of the tumour samples (fig 2A) shows that the overall haplotype distribution of PNETs deviates from the control group (Fisher exact test, $\mathrm{p}=0.014$ ), with a more than 10-fold over-representation of the H2 $\delta$ haplotype (Fisher exact test, $\mathrm{p}=0.004$ ). The ependymomas also display a 6.5-fold over-representation of the $\mathrm{H} 2 \delta$ haplotype (Fisher exact test, $\mathrm{p}=0.032$ ). No $\mathrm{H} 2 \delta$ haplotypes were detected among the diffuse astrocytomas or mixed gliomas/oligodendrogliomas.

The five PDGFRA promoter haplotypes can theoretically give rise to 15 different genotypes. With the exception of the rare $\mathrm{H} 2 \alpha / \mathrm{H} 2 \delta, \mathrm{H} 2 \beta / \mathrm{H} 2 \beta, \mathrm{H} 2 \beta / \mathrm{H} 2 \delta, \mathrm{H} 2 \gamma / \mathrm{H} 2 \gamma$, and $\mathrm{H} 2 \gamma / \mathrm{H} 2 \delta$ genotypes (expected frequencies of $2.2 \%, 0.5 \%, 0.2 \%, 0.2 \%$, and $0.1 \%$, respectively, based on the control sample population haplotype frequencies), all other genotypes were detected in our control sample population (data not shown). Although our statistical analysis is hampered by the low frequencies of most genotypes (the $\mathrm{H} 1 / \mathrm{H} 2 \alpha+\mathrm{H} 2 \alpha / \mathrm{H} 2 \alpha+\mathrm{H} 2 \alpha$ ) $\mathrm{H} 2 \beta$ genotypes make up $86.9 \%$ of all genotypes), we generally do not see any differences in genotype frequencies between tumour groups and controls (data not shown), with the

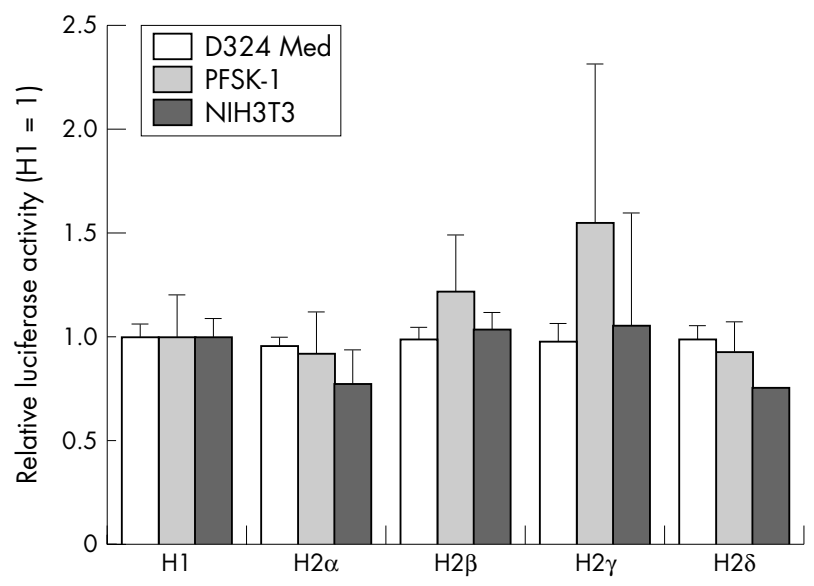

Figure 3 Analysis of haplotype specific promoter activity. The -1589/ +118 haplotype specific PDGFRA promoter-luciferase constructs were transiently transfected to the cells indicated. Luciferase levels were determined $48 \mathrm{~h}$ post-transfection and normalised for the $\beta$-galactosidase activity of the cotransfected $\beta$-actin promoter-LacZ plasmid. The luciferase values are relative to the luciferase activity of the $\mathrm{H} 1$ promoter. Error bars indicate standard deviation of four (PFSK-1) or two (NIH3T3 and D324 Med) independent experiments. exception of the $\mathrm{H} 2 \delta$-containing genotypes. The $\mathrm{H} 2 \delta$ haplotype is represented by an A at the SNP4 position (fig 1). As shown in fig $2 \mathrm{~B}$, we do observe a significant overrepresentation of $\mathrm{H} 2 \delta$ heterozygotes (AC) in the ependymal tumour group compared to controls (Fisher exact, $p=0.047$ ), which is exclusively caused by the $\mathrm{H} 2 \delta$ heterozygote over-representation in the ependymomas (Fisher exact, $\mathrm{p}=0.007)$. In addition, the PNETs show a tendency of $\mathrm{H} 2 \delta$ homozygote (AA) over-representation (Fisher exact, 0.066).

We have no indications that our haplotype and genotype data are affected by tumour specific deletions of PDGFRA. Analysis of the paired blood (where available) for the homozygous medulloblastoma (9 of 17) and PNET (5 of 9) samples resulted in the same haplotype/genotype as the corresponding tumour material (data not shown). Thus, in most (if not all) cases the tumour PDGFRA promoter haplotype/genotype also represents the normal genetic constitution of the patient.

\section{Analysis of haplotype specific PDGFRA promoter activity}

To investigate whether the $\mathrm{H} 2 \delta$ haplotype confers a different activity on the PDGFRA promoter (as compared to the other haplotypes), we transfected all five haplotype specific PDGFRA promoter-luciferase plasmids into the medulloblastoma cell line D324 Med ${ }^{32}$ and the PNET cell line PFSK-1,33 and measured the promoter activity. As shown in fig 3, we did not see any difference in activity between the plasmids. The same result was obtained when the plasmids were transfected into the mouse fibroblast cell line NIH3T3.

\section{Differential protein binding to the SNP4 region}

The $\mathrm{H} 2 \delta$ haplotype has a unique A nucleotide at the SNP4 position, compared to the $\mathrm{C}$ nucleotide at this position for all the other haplotypes (fig 1). We designed double stranded oligonucleotides for this region to identify possible differences in protein binding between the SNP4-C and SNP4$\mathrm{A}(\mathrm{H} 2 \delta)$ promoter haplotype. EMSAs, using nuclear extracts from PFSK-1 cells, and an SNP4-C oligonucleotide probe, showed a distinct protein-DNA complex (arrow, fig 4A). This protein-DNA complex disappears upon competition with an unlabelled SNP4-C oligonucleotide but not with an SNP4$\mathrm{A}(\mathrm{H} 2 \delta)$ oligonucleotide. The inability of the SNP4-A(H2 $\delta)$ oligonucleotide to bind this protein is also demonstrated in fig 4B, where no DNA-protein complex can be detected with the SNP4-A $(\mathrm{H} 2 \delta)$ oligonucleotide as probe. In addition, the protein-DNA complex is zinc dependent, since the zinc chelator phenanthroline completely prevents the formation of the complex (fig 4A, lanes 4 and 5).

We used the Genomatix MatInspector protocol ${ }^{30}$ to identify transcription factors which could potentially bind to the SNP4 containing sequence (fig 4C). Using the SNP4-C oligonucleotide sequence as input, we identified ZNF148 and NGFI-C as potential transcription factors binding to this region. Using the SNP4-A(H2 $\mathrm{H})$ oligonucleotide as input sequence we only identified a potential binding site for NGFI-C. Thus, it appears that the putative ZNF148 binding site is destroyed in the SNP4-A(H2 $\delta)$ haplotype promoter compared to the other promoter haplotypes. In addition, the ZNF148 binding site is conserved in both the mouse and rat Pdgfra promoter sequence (data not shown).

Based on the zinc dependence and on the difference in affinity for the SNP4-C sequence compared to the SNP4-A sequence, we further investigated the possibility that the SNP4-C binding factor is ZNF148. The addition of a ZNF148 antibody abolished much of the typical DNA-protein complex and also resulted in a "supershifted" complex (fig 4B, lane 4). In addition, an unlabelled oligonucleotide containing a mutation in one of the essential five cytidines in the ZNF148 


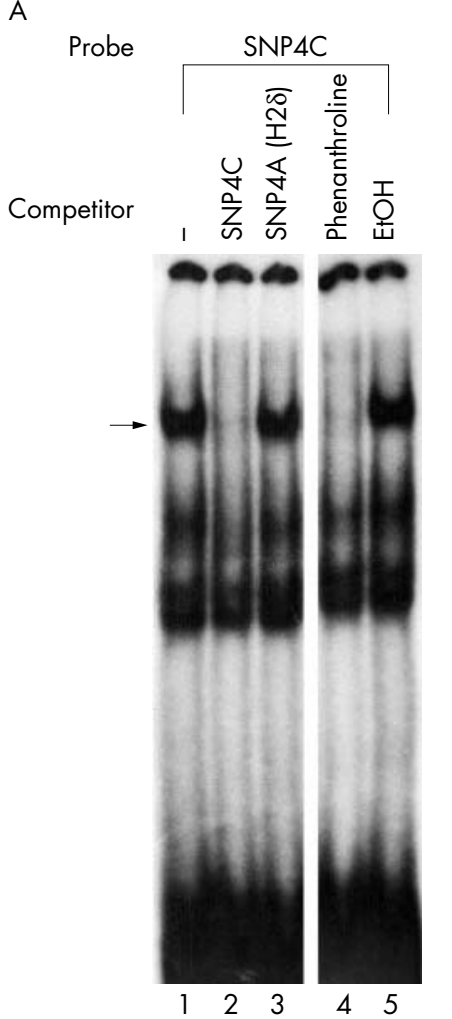

B
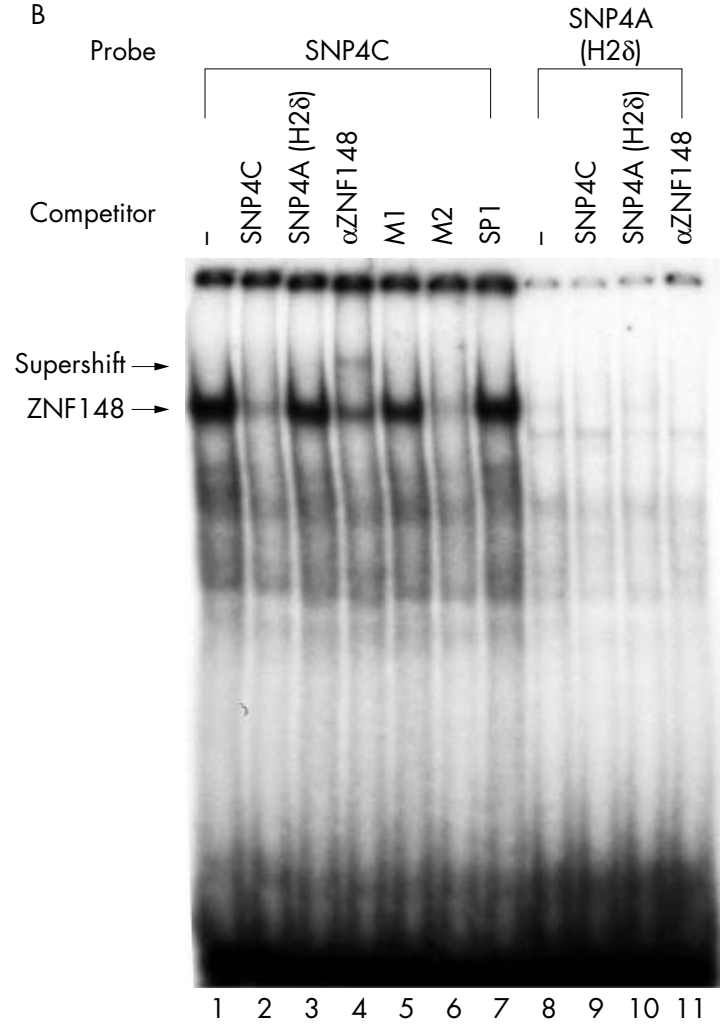

C

$$
\begin{aligned}
& \stackrel{A}{A} \stackrel{A}{\uparrow} \stackrel{M 2}{M} \\
& \text { g c C C + C C C C n }
\end{aligned}
$$

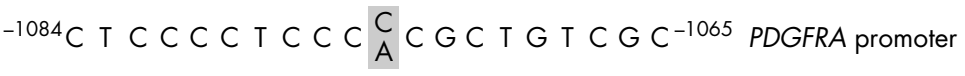

$$
\begin{aligned}
& \text { c C r C C A C GC a w } \\
& \text { NGFIC.01 } \\
& \text { c c n C C C C }
\end{aligned}
$$

Figure 4 Characterisation of PDGFRA promoter haplotype specific protein binding. (A) Nuclear extracts from PFSK-1 cells were incubated with a radiolabelled SNP4-C oligonucleotide. A 200 -fold molar excess of either unlabelled SNP4-C or SNP4-A oligonucleotide was added as indicated (lanes 2 and 3). In lanes 4 and 5 the nuclear extracts were incubated with either the zinc chelator phenantroline or its solvent (ethanol) as described. ${ }^{51}$ The arrow indicates the specific protein-DNA complex formed. (B) Nuclear extracts from PFSK-1 cells were incubated with a radiolabelled SNP4-C or SNP4-A oligonucleotide. A 200-fold molar excess of unlabelled oligonucleotides or $1 \mu \mathrm{l}$ of a ZNF148 antibody ${ }^{52}$ was added where indicated. The lower arrow indicates the DNA-ZNF148 complex, while the upper arrow indicates the DNA-ZNF148-antibody complex (supershift). (C) Sequence alignment of the SNP4 oligonucleotide sequence (PDGFRA promoter) and the consensus sequences for NGFI-C (NGFIC.01) and ZNF148 (ZBP89.01) binding sites derived from the Matlnspector database. Above the SNP4 oligonucleotide sequence is a more stringent ZNF148 consensus binding sequence. ${ }^{42}$ The polymorphic SNP4 nucleotide has been shaded. Also indicated are the positions of the oligonucleotide mutations $M 1$ and M2 that have been used in the experiment shown in fig 4B. Numbers refer to the position relative to the transcription start site (GenBank accession no. X80389).

binding sequence (Ml, fig 4C) did not compete with the labelled SNP4-C oligonucleotide for ZNF148 binding (fig 4B, lane 5), indicating a lack of affinity of ZNF148 for the Ml sequence. An oligonucleotide containing a mutation in a non-essential nucleotide (M2, fig 4C) fully competed for ZNF148 binding (fig 4B, lane 6), indicating a strong affinity of ZNF148 for the M2 sequence. In addition, ZNF148 did not display affinity for an oligonucleotide containing a consensus SPl sequence.

\section{DISCUSSION}

In this study we have examined the association of PDGFR $\alpha$ gene promoter polymorphisms with the occurrence of brain tumours. We initially set out to investigate the possibility of geographically specific differences in PDGFRA haplotype frequency distribution by analysing a Swedish control sample population. If we compare our data with those generated from a Dutch control population, ${ }^{24}$ we do see significant differences for the two major haplotypes $\mathrm{Hl}$ and $\mathrm{H} 2 \alpha$ but not for any of the other haplotypes. The $\mathrm{Hl}$ frequency is lower (0.1978 $v 0.3052, \mathrm{p}=0.023, \chi^{2}$ test Hl $v$ other haplotypes) and the $\mathrm{H} 2 \alpha$ frequency is higher $(0.6758 v 0.5714, \mathrm{p}=0.049$, $\chi^{2}$ test $\mathrm{H} 2 \alpha v$ other haplotypes) in the Swedish control group compared to the Dutch. Our Swedish Hl frequency is also much lower than a recently published $\mathrm{Hl}$ frequency of 0.3189 in a Hispanic population along the Texas-Mexico border. ${ }^{34}$ However, if we compare our control group $\mathrm{Hl}$ haplotype frequencies to those found in a large Northern Irish $(\mathrm{Hl}=$ $0.225)$ and French $(\mathrm{Hl}=0.209)$ control sample population, ${ }^{31}$ we do not observe any differences. Thus, it remains to be seen whether there are major differences in PDGFRA promoter haplotype distributions among different populations.

The most salient result from our PDGFRA promoter haplotype analysis is the specific over-representation of the $\mathrm{H} 2 \delta$ haplotype and genotype in patients with PNETs and ependymomas, which suggests a functional role for the $\mathrm{H} 2 \delta$ 
haplotype in the development of these tumours. The most obvious consequence of the $\mathrm{H} 2 \delta$ promoter haplotype would be that it affects PDGFRA transcription as compared to the other haplotypes. Although we were unsuccessful in demonstrating such a haplotype specific difference in promoter activity in transient transfection assays with promoterreporter plasmids, we did identify a $\mathrm{H} 2 \delta$ promoter specific inability to bind the transcription factor ZNF148.

Haplotype specific differences in PDGFRA promoter activity have been demonstrated previously in human U2-OS osteosarcoma cells. Transfected promoter-reporter plasmids showed that the $\mathrm{H} 2 \alpha$ and $\mathrm{H} 2 \beta$ promoters display much higher transcriptional activities than the $\mathrm{Hl}, \mathrm{H} 2 \gamma$, and $\mathrm{H} 2 \delta$ promoters. ${ }^{24}$ We do not have a good explanation as to why no haplotype specific activity difference could be demonstrated in our transfection assays. It may be that the PFSK-1 and D324 Med cells are not capable of showing ZNF148 dependent transcriptional differences, even though both PFSK-1 and D324 Med cells express both PDGFR $\alpha^{14}$ and intact ZNF148 (data not shown). However, the haplotypespecific transcription may require transcription factors not available in these cell lines. In addition, the assay used is not capable of showing any differences that require the environment of an intact tissue (to detect spatio-temporal and tissue specific transcriptional processes) or the placement of the promoter within the genome.

ZNF148 (also known as ZFP148, BFCOLl, BERF-1, and ZBP-89) belongs to the Krüppel-like zinc finger proteins and can either activate ${ }^{35-39}$ or repress ${ }^{40-46}$ the activity of a number of different promoters. ZNF148 is highly expressed in the neural tube during mouse embryogenesis. The in vivo function of ZNF148 in the mouse neural tube remains unknown, since mutated ZNF148 alleles are not transmitted in the germ-line, due to the requirement of two functional ZNF148 alleles for the normal development of fetal germ cells. ${ }^{47}$ The repressor activity of ZNF148 is often related to its inhibitory action on the activating transcription factor SPI through competition with adjacent or overlapping binding sequences. Interestingly, a putative SPl binding site also overlaps with the ZNF148 binding sequence in the PDGFRA promoter (data not shown), but we have no data suggesting a role for SPI in PDGFRA transcription.

The remarkable aspect of the $\mathrm{H} 2 \delta$ over-representation is its tumour specificity. What do the PNETs and ependymomas have in common and what makes them different from the other tumours? In this context it is interesting to note that if we combine the haplotype distribution of the astrocytomas and oligodendrogliomas/mixed gliomas, this group is similar to the controls but significantly different from the PNETs and ependymomas (Fisher exact $5 \times 2, p=0.001$ and $p=0.037$, respectively). The $\mathrm{H} 2 \delta$ genotype distribution of the astrocytomas-oligodendrogliomas/mixed gliomas is also similar to the controls but can be clearly distinguished from the PNETs and ependymomas (Fisher exact $2 \times 2, \quad \mathrm{p}=0.029$ and $\mathrm{p}=0.007$, respectively; fig 2 ).

One possibility would be that PNETs and ependymomas are derived from the same or similar precursor cell population. The observation that PNETs and ependymomas (but also the other brain tumours studied) frequently show PDGFR $\alpha$ expression may actually reflect the characteristics of their precursor cells. Although it is far from clear what the precursor cells are for these tumours, the primitive neuroectodermal characteristics of PNETs makes it likely that they are derived from neural progenitor cells. It has been shown that both cultured nestin positive neural stem cells and early neuroepithelial cells in vivo express PDGFR $\alpha,{ }^{348}$ and PDGF signalling is involved in neuronal differentiation, proliferation, and migration of such stem cells..$^{48-50}$ Thus, it may be that the $\mathrm{H} 2 \delta$ haplotype promoter influences the level and/or timing of PDGFR $\alpha$ protein production in the normal progenitors and/or tumour precursors.

In summary, our data demonstrate that both PNET and ependymoma patients display an over-representation of the $\mathrm{H} 2 \delta$ PDGFRA promoter haplotype. The $\mathrm{H} 2 \delta$ promoter has a characteristic disruption of the ZNF148 binding site. Together, these results indicate a potential role for the ZNF148/PDGFRA pathway in the etiology of both PNETs and ependymomas. A further investigation of this pathway may lead to a better understanding of the biology of these tumours.

\section{ACKNOWLEDGEMENTS}

The authors would like to thank Gudrun Jonasdottir, Hans Garmo, and Jonas Nilsson for statistical advice, Juanita Merchant and David Law for the ZNF148 antibody, Joop van Zoelen for the promoterluciferase plasmids, and Patrick Buckley for critically reading the manuscript.

\section{Authors' affiliations}

C De Bustos, M Nistér, G Afink, Department of Genetics and Pathology, Uppsala University, Rudbeck Laboratory, 75185 Uppsala, Sweden

A Smits, Department of Neuroscience, Neurology, Uppsala University, University Hospital, 75185 Uppsala, Sweden

B Strömberg, Department of Women and Child Health, Uppsala University, University Children's Hospital, 75185 Uppsala, Sweden

V P Collins, Department of Pathology, University of Cambridge,

Addenbrooke's Hospital, Cambridge CB2 QQ, UK

M Nistér, G Afink, Department of Oncology-Pathology, Karolinska Institutet, Cancer Center Karolinska, R8:05 Karolinska Hospital, 17176 Stockholm, Sweden

This work was supported by the Swedish Children's Cancer Foundation (GA and MN); the Karolinska Institute Research Fund (GA); the James S. McDonnell Foundation, the Stockholm Cancer Society, and the Juvenile Diabetes Research Foundation (MN); the Samantha Dickson Research Trust, the Carly Watson Ependymoma Fund, Cancer Research UK, and the Jacqueline Seroussi Memorial Foundation for Cancer Research (VPC). CDB is supported by a fellowship from the Department of Education, Universities and Research of the Basque Government.

Competing interests: none declared

\section{REFERENCES}

1 Betsholtz C. Biology of platelet-derived growth factors in development. Birth Defects Res Part C Embryo Today 2003;69:272-85.

2 Oumesmar BN, Vignais L, Baron-Van Evercooren A. Developmental expression of platelet-derived growth factor alpha-receptor in neurons and glial cells of the mouse CNS. J Neurosci 1997;17:125-39.

3 Andrae J, Hansson I, Afink GB, Nister M. Platelet-derived growth factor receptor-alpha in ventricular zone cells and in developing neurons. Mol Cell Neurosci 2001;17:1001-13.

4 Heldin CH, Westermark B. Mechanism of action and in vivo role of plateletderived growth factor. Physiol Rev 1999;79:1283-316.

5 Hermanson M, Funa K, Hartman M, Claesson-Welsh L, Heldin $\mathrm{CH}_{\text {, }}$ Westermark B, Nister M. Platelet-derived growth factor and its receptors in human glioma tissue: expression of messenger RNA and protein suggests the presence of autocrine and paracrine loops. Cancer Res 1992;52:3213-9.

6 Guha A, Dashner K, Black PM, Wagner JA, Stiles CD. Expression of PDGF and PDGF receptors in human astrocytoma operation specimens supports the existence of an autocrine loop. Int J Cancer 1995;60:168-73.

7 Lokker NA, Sullivan CM, Hollenbach SJ, Israel MA, Giese NA. Plateletderived growth factor (PDGF) autocrine signaling regulates survival and mitogenic pathways in glioblastoma cells: evidence that the novel PDGF-C and PDGF-D ligands may play a role in the development of brain tumors. Cancer Res 2002;62:3729-35.

8 Robinson S, Cohen M, Prayson R, Ransohoff RM, Tabrizi N, Miller RH Constitutive expression of growth-related oncogene and its receptor in oligodendrogliomas. Neurosurgery 2001;48:864-884

9 Di Rocco F, Carroll RS, Zhang J, Black PM. Platelet-derived growth factor and its receptor expression in human oligodendrogliomas. Neurosurgery 1998:42:341-6.

10 Black P, Carroll R, Glowacka D. Expression of platelet-derived growth factor transcripts in medulloblastomas and ependymomas. Pediatr Neurosurg 1996;24:74-8

11 Nister M, Claesson-Welsh L, Eriksson A, Heldin CH, Westermark B. Differential expression of platelet-derived growth factor receptors in human malignant glioma cell lines. J Biol Chem 1991;266:16755-63.

12 Hermanson M, Funa K, Koopmann J, Maintz D, Waha A, Westermark B, Heldin CH, Wiestler OD, Louis DN, von Deimling A, Nister M. Association of loss of heterozygosity on chromosome $17 p$ with high platelet-derived growth 
factor alpha receptor expression in human malignant gliomas. Cancer Res 1996;56:164-71.

13 Smits A, van Grieken D, Hartman M, Lendahl U, Funa K, Nister M. Coexpression of platelet-derived growth factor alpha and beta receptors on medulloblastomas and other primitive neuroectodermal tumors is consistent with an immature stem cell and neuronal derivation. Lab Invest 1996;74:188-98.

14 Andrae J, Molander C, Smits A, Funa K, Nister M. Platelet-derived growth factor- $B$ and $-C$ and active alpha-receptors in medulloblastoma cells. Biochem Biophys Res Commun 2002;296:604-11.

15 Dai C, Celestino JC, Okada Y, Louis DN, Fuller GN, Holland EC. PDGF autocrine stimulation dedifferentiates cultured astrocytes and induces oligodendrogliomas and oligoastrocytomas from neural progenitors and astrocytes in vivo. Genes Dev 2001;15:1913-25.

16 Uhrbom L, Hesselager G, Nister M, Westermark B. Induction of brain tumors in mice using a recombinant platelet-derived growth factor B-chain retrovirus. Cancer Res 1998;58:5275-9.

17 MacDonald TJ, Brown KM, LaFleur B, Peterson K, Lawlor C, Chen Y, Packer RJ, Cogen P, Stephan DA. Expression profiling of medulloblastoma: PDGFRA and the RAS/MAPK pathway as therapeutic targets for metastatic disease. Nat Genet 2001;29:143-52.

18 Reinertsen KK, Bronson RT, Stiles CD, Wang C. Temporal and spatial specificity of PDGF alpha receptor promoter in transgenic mice. Gene Expr 1997;6:301-14.

19 Zhang XQ, Afink GB, Svensson K, Jacobs JJ, Gunther T, Forsberg-Nilsson K, van Zoelen EJ, Westermark B, Nister M. Specific expression in mouse mesoderm- and neural crest-derived tissues of a human PDGFRA promoter/ lacZ transgene. Mech Dev 1998;70:167-80.

20 Joosten PH, Toepoel M, van Oosterhout D, Afink GB, van Zoelen EJ. A regulating element essential for PDGFRA transcription is recognized by neural tube defect-associated PRX homeobox transcription factors. Biochim Biophys Acta 2002;1588:254-60.

21 Afink G. Westermark UK, Lammerts E, Nister M. C/EBP is an essential component of PDGFRA transcription in MG-63 cells. Biochem Biophys Res Commun 2004;315:313-8.

22 Kitami Y, Fukuoka T, Hiwada K, Inagami T. A high level of CCAAT-enhancer binding protein-delta expression is a major determinant for markedly elevated differential gene expression of the platelet-derived growth factor-alpha receptor in vascular smooth muscle cells of genetically hypertensive rats. Circ Res 1999;84:64-73.

23 Wang C, Song B. Cell-type-specific expression of the platelet-derived growth factor alpha receptor: a role for GATA-binding protein. Mol Cell Biol 1996; 16:712-23.

24 Joosten PH, Toepoel M, Mariman EC, Van Zoelen EJ. Promoter haplotype combinations of the platelet-derived growth factor alpha-receptor gene
predispose to human neural tube defects. Nat Genet 2001;27:215-7.

25 Kleihues P, Cavenee WK. Pathology and genetics of tumors of the nervous system. Lyon: IARC Press, 2000.

26 Kleihues P, Louis DN, Scheithauer BW, Rorke LB, Reifenberger G, Burger PC, Cavenee WK. The WHO classification of tumors of the nervous system. J Neuropathol Exp Neurol 2002;61:215-29.

27 Miller SA, Dykes DD, Polesky HF. A simple salting out procedure for extracting DNA from human nucleated cells. Nucleic Acids Res 1988;16:1215.

28 Ichimura K, Schmidt EE, Goike HM, Collins VP. Human glioblastomas with no alterations of the CDKN2A (p16INK4A, MTS1) and CDK4 genes have frequent mutations of the retinoblastoma gene. Oncogene 1996;13:1065-72.

29 Afink GB, Nister M, Stassen BH, Joosten PH, Rademakers PJ, BongcamRudloff E, Van Zoelen EJ, Mosselman S. Molecular cloning and functional characterization of the human platelet-derived growth factor alpha receptor gene promoter. Oncogene 1995;10:1667-72.

30 Quandt K, Frech K, Karas H, Wingender E, Werner T. Matlnd and Matlnspector: new fast and versatile tools for detection of consensus matches in nucleotide sequence data. Nucleic Acids Res 1995;23:4878-84.

31 Herrmann SM, Ricard S, Nicaud V, Brand E, Behague I, Blanc H, Ruidavets JB, Evans A, Arveiler D, Luc G, Poirier O, Cambien F. Polymorphisms in the genes encoding platelet-derived growth factor $\mathrm{A}$ and alpha receptor. J Mol Med 2000;78:287-92.

32 Jacobsen PF, Jenkyn DJ, Papadimitriou JM. Establishment of a human medulloblastoma cell line and its heterotransplantation into nude mice. J Neuropathol Exp Neurol 1985;44:472-85.
33 Fults D, Pedone CA, Morse HG, Rose JW, McKay RD. Establishment and characterization of a human primitive neuroectodermal tumor cell line from the cerebral hemisphere. J Neuropathol Exp Neurol 1992;51:272-80.

34 Zhu H, Wicker NJ, Volcik K, Zhang J, Shaw GM, Lammer EJ, Suarez L, Canfield M, Finnell RH. Promoter haplotype combinations for the human PDGFRA gene are associated with risk of neural tube defects. Mol Genet Metab 2004;81:127-32.

35 Bai L, Merchant JL. Transcription factor ZBP-89 cooperates with histone acetyltransferase $\mathrm{p} 300$ during butyrate activation of $\mathrm{p} 21$ wafl transcription in human cells. J Biol Chem 2000;275:30725-33.

36 Hasegawa T, Takeuchi A, Miyaishi O, Isobe K, de Crombrugghe B. Cloning and characterization of a transcription factor that binds to the proximal promoters of the two mouse type I collagen genes. J Biol Chem 1997;272:4915-23.

37 Reizis B, Leder P. Expression of the mouse pre-T cell receptor alpha gene is controlled by an upstream region containing a transcriptional enhancer. J Exp Med 1999; 189: 1669-78.

38 Yamada A, Takaki S, Hayashi F, Georgopoulos K, Perlmutter RM, Takatsu K. Identification and characterization of a transcriptional regulator for the lck proximal promoter. J Biol Chem 2001;276:18082-9.

39 Ye S, Whatling C, Watkins H, Henney A. Human stromelysin gene promoter activity is modulated by transcription factor ZBP-89. FEBS Lett 1999;450:268-72.

40 Cheng PY, Kagawa N, Takahashi Y, Waterman MR. Three zinc finger nuclear proteins, Spl, Sp3, and a ZBP-89 homologue, bind to the cyclic adenosine monophosphate-responsive sequence of the bovine adrenodoxin gene and regulate transcription. Biochemistry 2000;39:4347-57.

41 Keates AC, Keates S, Kwon JH, Arseneau KO, Law DJ, Bai L, Merchant JL, Wang TC, Kelly CP. ZBP-89, Spl, and nuclear factor-kappa B regulate epithelial neutrophil-activating peptide-78 gene expression in Caco-2 human colonic epithelial cells. J Biol Chem 2001;276:43713-22.

42 Law GL, Itoh H, Law DJ, Mize GJ, Merchant JL, Morris DR. Transcription factor ZBP-89 regulates the activity of the ornithine decarboxylase promoter. J Biol Chem 1998;273:19955-64.

43 Law DJ, Tarle SA, Merchant JL. The human ZBP-89 homolog, located at chromosome 3q21, represses gastrin gene expression. Mamm Genome 1998:9:165-7.

44 Merchant JL, lyer GR, Taylor BR, Kitchen JR, Mortensen ER, Wang Z, Flintoft RJ, Michel JB, Bassel-Duby R. ZBP-89, a Kruppel-like zinc finger protein, inhibits epidermal growth factor induction of the gastrin promoter. Mol Cell Biol 1996; 16:6644-53.

45 Park H, Shelley CS, Arnaout MA. The zinc finger transcription factor ZBP-89 is a repressor of the human beta 2 -integrin CD1 $1 \mathrm{~b}$ gene. Blood 2003;101:894-902.

46 Passantino R, Antona V, Barbieri G, Rubino P, Melchionna R, Cossu G, Feo $S$, Giallongo A. Negative regulation of beta enolase gene transcription in embryonic muscle is dependent upon a zinc finger factor that binds to the G-rich box within the muscle-specific enhancer. J Biol Chem 1998;273:484-94.

47 Takeuchi A, Mishina Y, Miyaishi O, Kojima E, Hasegawa T, Isobe K. Heterozygosity with respect to $\mathrm{Zfpl} 48$ causes complete loss of fetal germ cells during mouse embryogenesis. Nat Genet 2003;33:172-6.

48 Forsberg-Nilsson K, Behar TN, Afrakhte M, Barker JL, McKay RD. Plateletderived growth factor induces chemotaxis of neuroepithelial stem cells. J Neurosci Res 1998;53:521-30.

49 Erlandsson A, Enarsson M, Forsberg-Nilsson K. Immature neurons from CNS stem cells proliferate in response to platelet-derived growth factor. J Neurosci $2001 ; 21: 3483-91$.

50 Park JK, Williams BP, Alberta JA, Stiles CD. Bipotent cortical progenitor cells process conflicting cues for neurons and glia in a hierarchical manner. J Neurosci 1999; 19:10383-9.

51 Wieczorek E, Lin Z, Perkins EB, Law DJ, Merchant JL, Zehner ZE. The zinc finger repressor, ZBP-89, binds to the silencer element of the human vimentin gene and complexes with the transcriptional activator, Spl. J Biol Chem 2000;275: 12879-88.

52 Taniuchi T, Mortensen ER, Ferguson A, Greenson J, Merchant JL. Overexpression of ZBP-89, a zinc finger DNA binding protein, in gastric cancer. Biochem Biophys Res Commun 1997;233:154-60. 